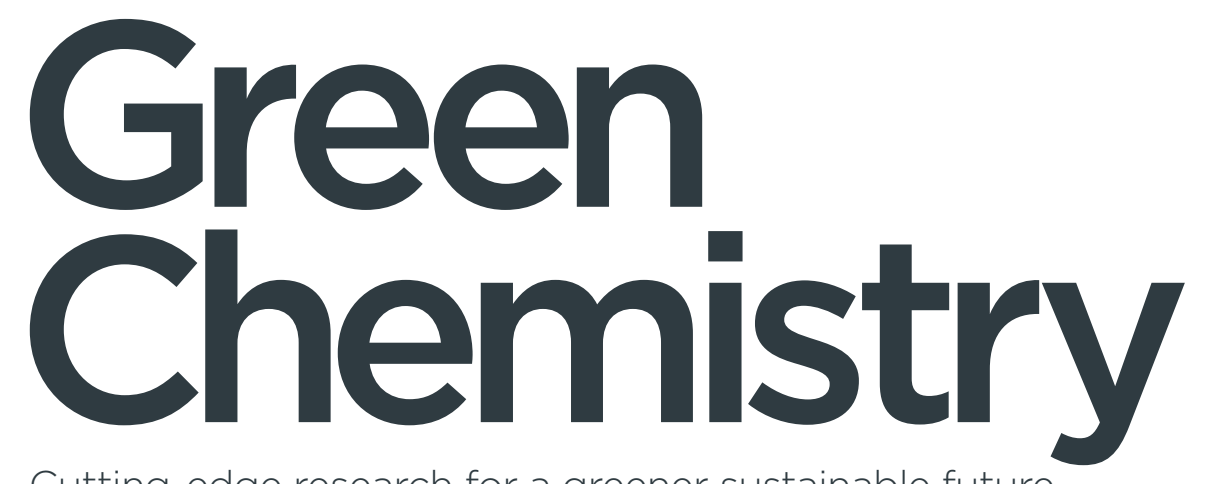

Volume 22

Number 23

7 December 2020

Pages 8049-8534

Cutting-edge research for a greener sustainable future

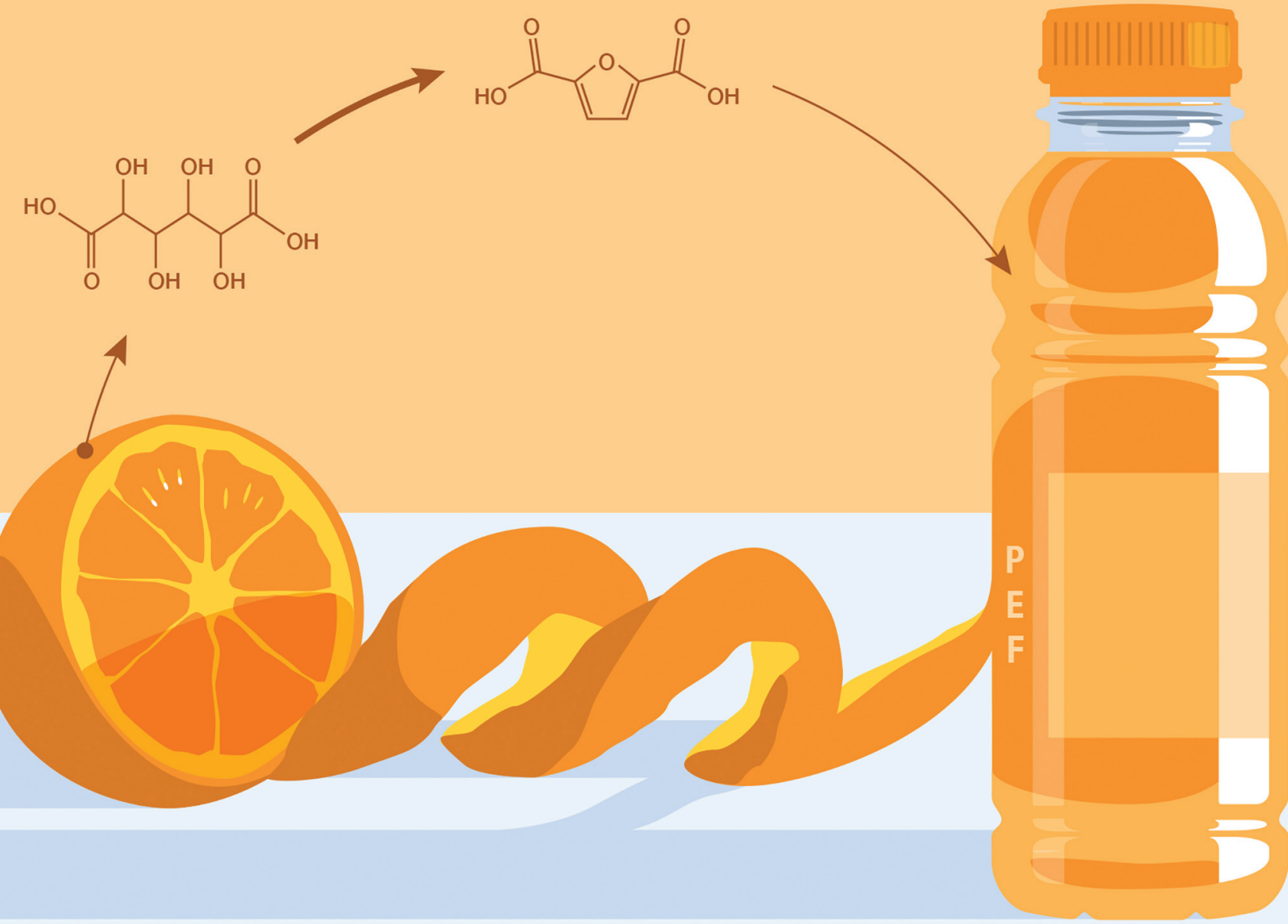




\section{D) Check for updates}

Cite this: Green Chem., 2020, 22, 8271

Received 6th July 2020,

Accepted 21st August 2020

DOI: $10.1039 / \mathrm{dOgc02293d}$

rsc.li/greenchem

\title{
A unique pathway to platform chemicals: aldaric acids as stable intermediates for the synthesis of furandicarboxylic acid esters $\uparrow$
}

\author{
Nicolaas van Strien, (D) Sari Rautiainen, (D) * Martta Asikainen, David A. Thomas, \\ Juha Linnekoski, Klaus Niemelä and Ali Harlin
}

\begin{abstract}
2,5-Furandicarboxylic acid (FDCA) has received attention as an emerging bio-based building block with many applications, especially in renewable polyesters. The common route to FDCA uses the unstable 5-hydroxymethylfurfural (HMF) as an intermediate. Here, we present an alternative route to FDCA and its esters using C6 aldaric acids as stable intermediates. Aldaric acids, or sugar diacids, can be obtained by the oxidation of $\mathrm{C} 6$ sugars or uronic acids from pectin. Subsequent dehydration of aldaric acids by solid acid catalysts in butanol produces furancarboxylates. Using silica-supported acid catalysts, over $90 \%$ yields of furancarboxylates were achieved with the selectivity to FDCA and its esters reaching $80 \%$.
\end{abstract}

\section{Introduction}

The shift from fossil-based polymers to renewable plastics requires new efficient methods for the production of monomers from biomass. 2,5-Furandicarboxylic acid (FDCA) and its esters are promising bio-based substitutes for terephthalic acid in the production of polyesters. ${ }^{1,2}$ Compared to fossilbased polyethylene terephthalate (PET), polyethylene furanoate (PEF) produced from FDCA has about 50\% lower carbon footprint. ${ }^{3}$ Furthermore, PEF polymers have superior gas barrier and mechanical properties compared to PET polymers. ${ }^{4}$ Of the PET components, mono-ethylene glycol (MEG) is currently available from renewable sources but no commercial production of bio-based terephthalic acid exists. ${ }^{5}$ Therefore, FDCA offers a compelling alternative for the production of $100 \%$ renewable polyesters. In addition, FDCA is rapidly gaining interest as a bio-based monomer for other applications such as polyurethanes ${ }^{6}$ and epoxy resins. ${ }^{7,8}$

The current methods for producing FDCA use a two-step process with edible sugars like glucose or fructose as feedstock (Scheme 1). ${ }^{2,9}$ The sugar is first dehydrated using an acid catalyst into 5-hydroxymethylfurfural (HMF) which is further oxidized into FDCA. In addition to competing with the food chain, a serious disadvantage is that the intermediate HMF is unstable and readily reacts further under acidic conditions to produce levulinic acid and insoluble humins. ${ }^{10}$ HMF yields

VTT Technical Research Centre of Finland Ltd, P.O. Box 1000, FI-02044 VTT, Finland. E-mail: sari.rautiainen@vtt.fi

$\dagger$ Electronic supplementary information (ESI) available. See DOI: 10.1039/ d0ge02293d often remain low and furthermore, isolation and purification of HMF from the polar reaction media are challenging. Although extensive efforts have been made to suppress the side reactions and enable high yields of the isolated HMF, the inherent instability of HMF makes it a challenging molecule for biorefineries. ${ }^{11-14}$ One alternative route has been developed by Avantium; the dehydration is carried out in methanol, producing methoxymethylfurfural (MMF) as the intermediate. ${ }^{15,16}$ Good selectivity and yield are obtained; currently, this process is being run on a pilot scale with plans having been announced for a commercial-scale plant. ${ }^{4}$ The oxidation of the intermediate to FDCA can be performed with high yields using noble metal catalysts or the Amoco process employing the Mn-Co-Br catalyst. ${ }^{9}$ Promising results have also been achieved using biocatalytic oxidation of HMF or MMF to FDCA. High yields have been reported under mild conditions; however, further development is needed to increase feedstock concentrations and shorten reaction times. ${ }^{17}$

Sugars derived from lignocellulosic feedstock or agricultural residues would avoid competition with food production. High HMF yields (up to 66\%) have been reported directly from cellulose using ionic liquids in combination with a Lewis acid catalyst. ${ }^{18}$ However, product separation and economical scaleup remain challenges. Recently, carboxylation of 2-furoic acid (FCA) into FDCA has also been reported. ${ }^{19}$ This presents an interesting alternative route for FDCA production, as furfural derived from lignocellulosic feedstock could be used as the intermediate for the previous steps in this process. Another recent example uses uronic acids derived from pectin for FDCA ester production via a three-step route including isomerisation, cyclodehydration and oxidation steps of the uronic acid. ${ }^{20}$ 


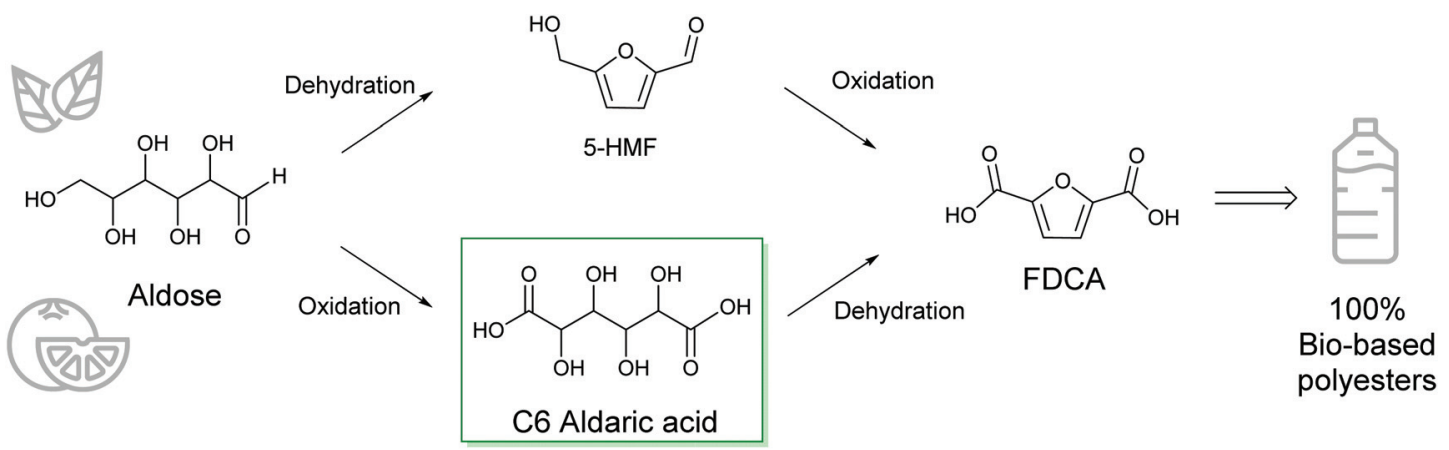

Scheme 1 Comparison of routes for FDCA synthesis via different intermediates.

Although formation of HMF is avoided, the overall yield of FDCA remains at $45 \%$.

The preparation of FDCA was reported in 1876 with galactaric acid (or mucic acid) as the substrate. ${ }^{21}$ In the original report, galactaric acid was heated in excess $\mathrm{HBr}$ and FDCA was obtained. Other authors have reported similar methods, where an excess of either $\mathrm{H}_{2} \mathrm{SO}_{4}$ or $\mathrm{HBr}$ was used to produce FDCA in around $50 \%$ yields. ${ }^{22,23}$ In more recent publications, an excess of benzene sulfonic acid or $p$-toluene sulfonic acid has been used for the dehydration of C6 aldaric acids to produce FDCA in around $50 \%$ yield. ${ }^{24-26}$ Zhao et al. reported a one-pot synthesis of diethyl furan-2,5-dicarboxylate using an excess of sulfonic acid followed by the addition of ethanol; $30 \%$ yield was obtained in $16 \mathrm{~h}$ after the two steps. ${ }^{26}$ With sub-stoichiometric amounts of the acid catalyst, up to $53 \%$ yields of FDCA were obtained. ${ }^{27,28}$ Taguchi et al. reported that heteropolyacids catalysed the dehydration at lower molar ratios compared to homogeneous acids; 44\% FDCA ester was obtained with $10 \mathrm{~mol} \%$ phosphotungstic acid in a $15 \mathrm{~h}$ reaction. ${ }^{28}$ These results show that aldaric acids are an interesting alternative for FDCA production, even though considerable improvements are needed for the methods to be industrially viable.

Aldaric acids have gained interest as value-added bio-based chemicals for the food, pharmaceutical and chemical industries; glucaric acid was listed by the DOE as one of the top value-added chemicals from biomass. ${ }^{29}$ Glucaric acid can be obtained by oxidation of glucose using a Pt catalyst ${ }^{30}$ or nitric acid $^{31}$ in up to $60 \%$ or $45 \%$ yields, respectively. In a recent paper, Thaore et al. discussed the techno-economic and lifecycle assessments of the two methods. ${ }^{32}$ While both methods were shown to be economically viable, the heterogeneously catalysed route showed $22 \%$ lower environmental impact compared to the nitric acid-mediated route. An alternative route to aldaric acids is the oxidation of uronic acids obtained from pectin-containing waste streams. Au catalysts are highly selective in the oxidation of uronic acids to aldaric acids, giving up to quantitative yields under very mild conditions. ${ }^{33-36}$ Galactaric acid can also be produced directly from pectin without extensive purification using benign biotechnical means. ${ }^{37-40}$

The diacid functionality of aldaric acids is especially attractive for renewable polyesters and polyamides. ${ }^{2}$ Much of the research on aldaric acid valorisation has focused on producing adipic acid, one of the monomers of Nylon-66. Rennovia's twostep process includes the Pt-catalysed oxidation of glucose to glucaric acid followed by hydrogenation in the presence of a noble metal catalyst and $\mathrm{HBr}^{30}$ Up to $60 \%$ and $89 \%$ yields were reported for the oxidation and hydrogenation steps, respectively. Adipic acid can also be produced from galactaric acid via muconic acid. ${ }^{41}$ Rhenium-catalysed deoxydehydration of galactaric acid can give up to quantitative yields of muconic acid in an alcohol solvent. ${ }^{42,43}$ Consecutive hydrogenation gives adipic acid in very high yields. In aqueous solutions, however, adipic acid yields remained low. ${ }^{44}$ Recycling of the precious Re catalyst was addressed by using an ionic liquid as a homogeneous support for the catalyst, giving an overall $91 \%$ yield of adipic acid. ${ }^{45}$

Here we show the efficient production of furancarboxylates from C6 aldaric acids (hexaric acids) using solid acid catalysts. In this recently patented process, ${ }^{46}$ over $95 \%$ total yields of furancarboxylates were obtained. The main products are the esters of FDCA and FCA, with the selectivity depending on the substrate, catalyst type and reaction conditions. Esterification prior to aromatisation increases the solubility and yield of the reaction. We show over $80 \%$ yield of FDCA esters, which to our knowledge is the highest reported yield of FDCA starting from aldaric acid esters (Scheme 2). The process uses an easily separable solid acid catalyst and $n$-butanol which is available from renewable sources. Furthermore, utilising pectin-derived galactaric acid expands the feedstock scope to many industry

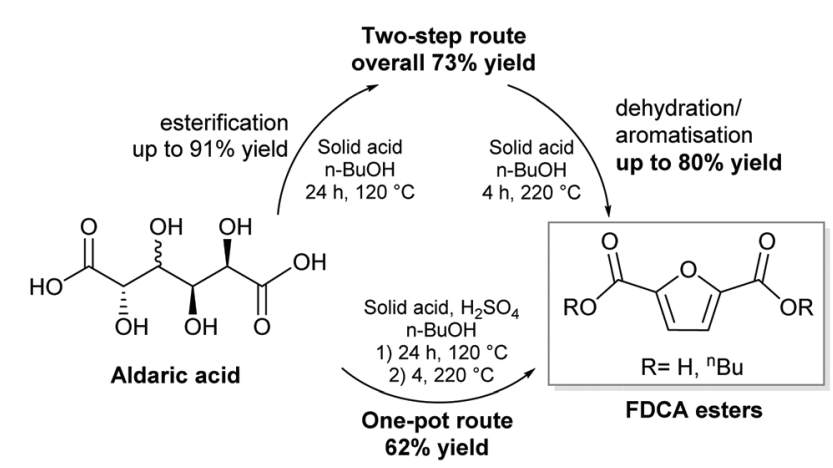

Scheme 2 Production of FDCA esters from aldaric acids using solid acid catalysts. 
side streams previously unusable for FDCA production. Using sulfuric acid as the co-catalyst, FDCA esters can be obtained in a one-pot process starting from aldaric acid.

\section{Results and discussion}

The dehydration of aldaric acid and consecutive formation of the furan ring take place under acidic conditions. Several families of solid acid catalysts were selected for the synthesis of furancarboxylates; acids supported on polymers, silica, alumina and zirconia were tested as well as acidic zeolites and clays. Many of the tested catalysts were obtained from commercial sources and some were prepared using methods previously reported in the literature (see the ESI $\dagger$ for more details). Previously, we have shown that also some transition metals, such as rhenium, can form furancarboxylates from aldaric acids but these catalysts favour deoxydehydration to linear muconic acid. ${ }^{46,47}$

Both glucaric acid and galactaric acid are stable crystalline compounds and poorly soluble in most solvents. The initial screening was performed with galactaric acid (1a) in $n$-butanol to improve the solubility by in situ ester formation. At $210{ }^{\circ} \mathrm{C}$, low conversions were achieved with only up to $7 \%$ furancarboxylates (Fig. S3†). Increasing the temperature to $230{ }^{\circ} \mathrm{C}$ increased the conversions; catalysts showing the desired activity towards aromatisation are shown in Fig. S4. $\dagger$ With sulfated zirconia, the furancarboxylate yields were very low. Sulfated alumina as well as Nafion NR50 clearly favoured the formation of furanmonocarboxylates, as was the case with silicotungstic acid. The most promising results were obtained with acids on silica carriers; phenyl sulfonic acid ethyl sulfide silica (PSAESS) gave furancarboxylates with $41 \%$ selectivity at $82 \%$ conversion (Table 1, entry 1). GC analyses of the silylated reaction mixtures showed that the main furan products were 2,5-furandicarboxylic acid $\mathbf{2 a}$ and its esters (2b, 2c) and 2-furanmonocarboxylates (3a, 3b). While both acid and ester forms of the furans were obtained, the ester forms were prevalent. It should be noted that all of the furandicarboxylates 2 can be used for polymerisation into PEF. On the other hand, the monocarboxylates 3 act as chain-terminating agents in polymerisation lowering the molecular weight of the polymer. For clarity, we have listed the selectivity to the separate products as well as the combined selectivity to furandicarboxylates 2 and furanmonocarboxylates 3 in Table 1 . Other products include isomers of the furandicarboxylates (Fig. S6†), probably 2,3-furandicarboxylic acid and its esters. ${ }^{28}$

The yields of 2 starting from 1a were quite modest, and the reason for this might be the low solubility of galactaric acid in the solvent $n$-butanol. Therefore, we decided to improve the solubility of the starting material by esterification with $n$ - $\mathrm{BuOH}$ prior to aromatisation. After refluxing in $n-\mathrm{BuOH}$ with an acid catalyst, the mixture was hot-filtered and evaporated to give 91\% isolated yield of galactaric di-butyl ester 1b with 91\% purity, with $5 \%$ monobutyl ester as the minor product (see the ESI $\dagger$ ). The resulting mixture was soluble in $n$-butanol at $70^{\circ} \mathrm{C}$, whereas the free acid 1a did not dissolve even at $150{ }^{\circ} \mathrm{C}$. We used this mixture in aromatisation without further purification.

The aromatisation reactions were carried out in stainless steel pressure reactors charged with 5 bar nitrogen and stirred with magnetic stirring at $300 \mathrm{rpm}$. During the reaction, the pressure increased to a maximum of 30 bar at $220^{\circ} \mathrm{C}$. When using $\mathbf{1 b}$ as the substrate, the selectivity to furandicarboxylates

Table 1 Aromatisation of galactaric acid and its butyl ester; the effect of the catalyst and reaction conditions

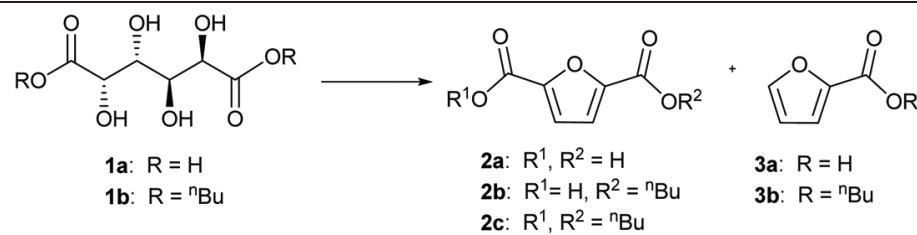

\begin{tabular}{|c|c|c|c|c|c|c|c|c|c|c|c|}
\hline Entry & Catalyst & $\begin{array}{l}\text { Cat. amount } \\
\text { (wt\%) }\end{array}$ & $\begin{array}{l}\text { Substrate } \\
\text { conc. (M) }\end{array}$ & $\begin{array}{l}\text { Conv. } \\
\text { (mol\%) }\end{array}$ & \multicolumn{7}{|c|}{ Selectivity (mol\%) } \\
\hline $1^{a}$ & PSAESS & 50 & 0.48 & 82 & 2 & 10 & 16 & 5 & 8 & 28 & 13 \\
\hline 3 & PSAESS & 50 & 0.31 & 95 & 2 & 18 & 54 & 2 & 15 & 74 & 17 \\
\hline 4 & Si-Propylsulfonic acid & 50 & 0.31 & 100 & 14 & 39 & 21 & 0 & 0 & 74 & $\mathbf{0}$ \\
\hline 5 & Si-Tosic acid & 50 & 0.31 & 100 & 1 & 10 & 46 & 2 & 11 & 57 & 13 \\
\hline 8 & Si-Tosic acid & 50 & 0.62 & 100 & 6 & 19 & 42 & 1 & 4 & 67 & 5 \\
\hline 9 & PSAESS & 5 & 0.62 & 94 & 2 & 19 & 54 & 3 & 20 & 75 & 23 \\
\hline 10 & Si-Tosic acid & 5 & 0.62 & 100 & 0 & 15 & 61 & 0 & 7 & 76 & 7 \\
\hline $11^{c}$ & Si-Tosic acid & 5 & 0.81 & 100 & 0 & 22 & 40 & 0 & 11 & 62 & 11 \\
\hline
\end{tabular}

Reaction conditions: substrate $\mathbf{1 b}, 10 \mathrm{ml} n$-butanol, $220{ }^{\circ} \mathrm{C}, 4 \mathrm{~h}, 5$ bar $\mathrm{N}_{2} \cdot{ }^{a}$ 1a as the substrate, $20 \mathrm{ml} n$-butanol, $230{ }^{\circ} \mathrm{C}, 2 \mathrm{~h} .{ }^{b} 20 \mathrm{ml} n$-butanol. ${ }^{c}$ One-pot reaction: $9.6 \mathrm{mmol} \mathrm{1a}, 12 \mathrm{ml} n$-butanol, $2.0 \mathrm{mmol} \mathrm{H}_{2} \mathrm{SO}_{4}, 24 \mathrm{~h}$ at $120^{\circ} \mathrm{C}$ followed by $4 \mathrm{~h}$ at $220^{\circ} \mathrm{C}$. 

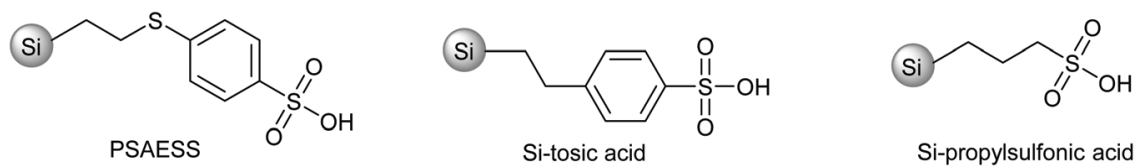

Si-propylsulfonic acid

Scheme 3 Structures of the silica-supported sulfonic acid catalysts.

2 doubled; PSAESS gave $66 \%$ selectivity at $85 \%$ conversion in $4 \mathrm{~h}$ (Table 1, entry 2). FDCA dibutyl ester 2c was the major product with $53 \%$ selectivity and the monoester $2 \mathbf{b}$ was formed with $13 \%$ selectivity. In addition, furanmonocarboxylates 3 were formed with $19 \%$ selectivity.

The higher solubility of $\mathbf{1 b}$ enabled increasing the substrate concentration, which is beneficial from both environmental and economic viewpoints. When the substrate concentration was doubled, $74 \%$ selectivity to 2 was achieved at 95\% conversion (Table 1, entry 3). In addition to PSAESS, two other silicasupported sulfonic acid catalysts, Si-propylsulfonic acid and Sitosic acid, were studied under similar conditions (Scheme 3). These catalysts gave full conversion and furandicarboxylates 2 were obtained with $74 \%$ and $57 \%$ selectivity, respectively (Table 1, entries 4 and 5). Interestingly, no decarboxylation products 3 were detected when using Si-propylsulfonic acid. Further doubling the substrate concentration gave full conversion with all three catalysts. In the case of PSAESS, $80 \%$ of furandicarboxylates 2 were obtained (entry 6), which is to our knowledge the highest FDCA yield reported starting from aldaric acid esters. Taking into account the esterification, the overall yield from galactaric acid over the two steps is $73 \%$. SiPropylsulfonic acid gave only $51 \%$ selectivity to 2 (entry 7 ), much lower than in the more dilute solution. With Si-tosic acid, the selectivity to 2 increased to $67 \%$ (entry 8 ).

Differences between the catalysts are mainly related to the acid strength and hydrophobicity; the density of acid sites of the three catalysts is in a similar range, 0.6-0.9 $\mathrm{mmol} \mathrm{g}^{-1}$ (Scheme 3). Si-Propylsulfonic acid is slightly less acidic and more hydrophobic compared to PSAESS and Si-tosic acid, ${ }^{48}$ which could reduce interactions with the polar reactants, e.g. reducing the amount of decarboxylation. However, with higher substrate concentration, this also leads to lower selectivity. The difference between PSAESS and Si-tosic acid is a thioether bridge, which has been shown to have a promoting effect in fructose dehydration. ${ }^{49}$ In this work, PSAESS gives the highest selectivity to 2 but also more of unfavourable decarboxylation. In a blank experiment without an acid catalyst, 7\% yield of 2 was obtained, confirming the crucial role of the catalyst (Table $\mathrm{S} 1 \dagger$ ).

As quite high catalyst amounts were used in the previous experiments, we wanted to optimise the process by reducing the catalyst amounts. Using PSAESS and Si-tosic acid, we decreased the catalyst loading from $50 \mathrm{wt} \%$ to $5 \mathrm{wt} \%$ (Fig. 1). With PSAESS, the conversion and selectivity to 2 dropped slightly and $75 \%$ yield of 2 was obtained with $5 \mathrm{wt} \%$ (corresponding to $c a .1 \mathrm{~mol} \%$ ) catalyst (Table 1 , entry 9 ). In addition, decarboxylation increased giving up to $23 \%$ of 3 as the side

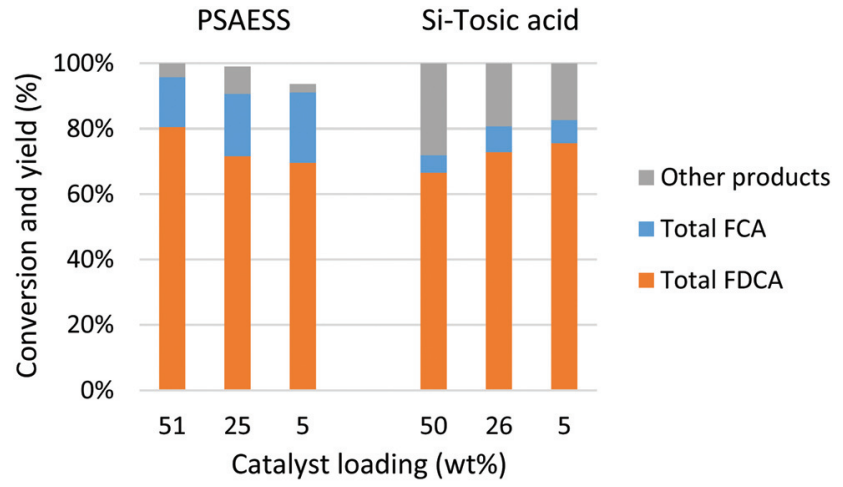

Fig. 1 Optimising the catalyst amount in $1 \mathrm{~b}$ aromatisation using PSAESS and Si-tosic acid. Reaction conditions: $6.2 \mathrm{mmol} 1 \mathrm{~b}, 10 \mathrm{ml}$ n-butanol, $220^{\circ} \mathrm{C}, 4 \mathrm{~h}$.

product. Remarkably, Si-tosic acid behaved the opposite; the selectivity to furandicarboxylates increased with decreased catalyst amount and 76\% yield of 2 was achieved with $5 \mathrm{wt} \%$ (1 mol\%) catalyst (entry 10). Furthermore, decarboxylation into 3 occurred to a lesser extent with Si-tosic acid compared to PSAESS.

To reduce the number of steps needed, we wanted to combine the esterification and aromatisation into a one-pot, two-step process. Based on the previous results, we chose to concentrate on Si-tosic acid as the preferred catalyst. Knowing that Si-tosic acid can also catalyse the esterification of aldaric acids, we used the conditions for esterification $\left(24 \mathrm{~h}\right.$ at $\left.120^{\circ} \mathrm{C}\right)$ in the first stage, followed by the aromatisation stage at higher temperature $\left(4 \mathrm{~h}, 220{ }^{\circ} \mathrm{C}\right)$. The substrate $\mathbf{1 a}$, catalyst and solvent were all loaded into the autoclave at the start of the reaction. In our first attempt, both the conversion and selectivity were considerably lower than when starting from $\mathbf{1 b}$ (Fig. 2); less than $20 \%$ yield of 2 was obtained using $5 \mathrm{wt} \% \mathrm{Si}-$ tosic acid. Increasing the catalyst amount to $15 \mathrm{wt} \%$ gave $55 \%$ yield of 2 at $97 \%$ conversion. However, decarboxylation was more pronounced and up to $30 \%$ of 3 was formed. The blank experiment with no catalyst gave only $7 \%$ diester $\mathbf{1 b}$ under similar conditions (Table S1†). To aid the reaction as well as to increase the solubility of $1 \mathbf{a},{ }^{42}$ we used sulfuric acid as the cocatalyst in the reaction. Indeed, $62 \%$ of 2 was formed at full conversion with $21 \mathrm{~mol} \%$ sulfuric acid and $5 \mathrm{wt} \%$ Si-tosic acid (Table 1, entry 11). Furthermore, the selectivity to monocarboxylates 3 decreased to $11 \%$. We are currently improving the onepot reaction conditions e.g. by further optimising the esterification step. However, this is to our knowledge the highest amount of furandicarboxylates obtained from aldaric acid in a one-pot catalytic process. 


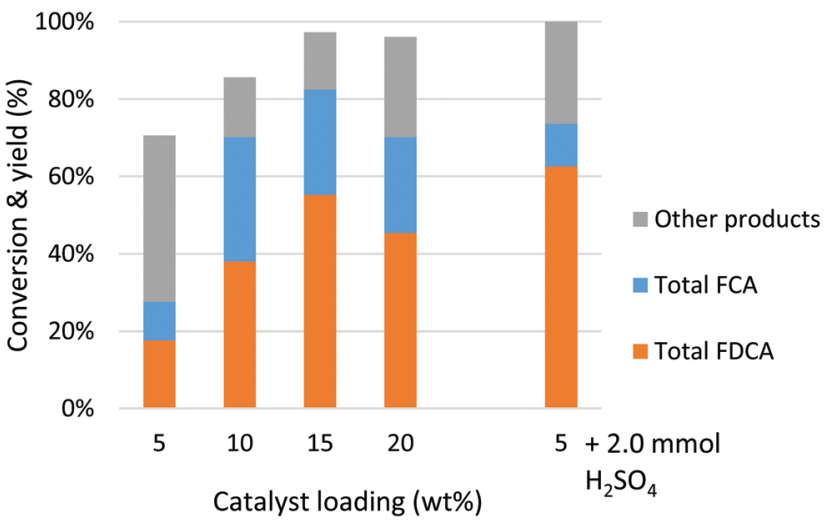

Fig. 2 One-pot esterification and aromatisation of 1a using Si-tosic acid. Reaction conditions: $9.6 \mathrm{mmol} 1 \mathrm{a}, 12 \mathrm{ml} n$-butanol, $24 \mathrm{~h}$ at $120^{\circ} \mathrm{C}$ followed by $4 \mathrm{~h}$ at $220^{\circ} \mathrm{C}$. Total column height represents conversion.

Next, we wanted to expand the substrate scope to glucaric acid, which can be produced by oxidation of glucose. Attempts to use the commercially available glucaric acid potassium salt directly in the aromatisation step failed. Glucaric acid readily forms lactones under acidic conditions, which could prevent further reaction. ${ }^{50}$ Esterification of glucaric acid potassium salt with $n$-BuOH using sulfuric acid gave a mixture containing $39 \%$ dibutyl glucarate and 51\% monobutyl glucarolactones (see the ESI $\dagger$ ). Aromatisation of this mixture 4 gave 2 with $c a$. $50 \%$ selectivity at full conversion with both PSAESS and Sitosic acid as catalysts (Table 2, entries 1 and 2). Reducing the catalyst amount to $5 \mathrm{wt} \%$ Si-tosic acid gave furanmonocarboxylates 3 as the main product with $37 \%$ selectivity and 2 with only $27 \%$ selectivity (entry 3 ). The glucarolactones in 4 probably cause lower reactivity compared to $\mathbf{1 b}$. In addition, decarboxylation is clearly more pronounced starting from 4 than in the case of $\mathbf{1 b}$. Gratifyingly, the addition of a catalytic amount of sulfuric acid increased the selectivity and decreased decarboxylation considerably; up to $70 \%$ of furandicarboxylates were obtained using Si-tosic acid and $27 \mathrm{~mol} \% \mathrm{H}_{2} \mathrm{SO}_{4}$ (entries 4 and 5). An experiment with only sulfuric acid as the catalyst gave $50 \%$ of 2 (entry 6 ). Similar yields were reported by Taguchi et al. with 2 equivalents of $\mathrm{H}_{2} \mathrm{SO}_{4}$ in an 8 h reaction. ${ }^{28}$ However, we also detected the formation of $24 \mathrm{wt} \%$ of insoluble char which had not been detected in the previous experiments. Evidently, the use of a solid acid together with sulfuric acid is beneficial for the reaction.

\section{Conclusions}

We have shown here that aldaric acids are an attractive starting material for producing FDCA as a renewable building block. Aldaric acids can be obtained from currently underutilised pectin-containing side-streams or from glucose by oxidation. Subsequent dehydration of the aldaric acids using solid acid catalysts produces furancarboxylates in high yields. Importantly, this route avoids the use of unstable HMF as the intermediate in FDCA production. We carried out the dehydration of galactaric and glucaric acid with silica-supported solid acid catalysts in $n$-butanol at temperatures above $200{ }^{\circ} \mathrm{C}$. Esterification of aldaric acids with an alcohol solvent prior to aromatisation increases the solubility and facilitates the reaction. The best results were obtained with phenyl sulfonic acid ethyl sulfide silica (PSAESS) and Si-tosic acid; over $80 \%$ yields of FDCA and its esters were achieved from galactaric acid ester. Considering the esterification of galactaric acid, an overall yield of $73 \%$ FDCA esters was achieved. Esterification of glucaric acid gave a mixture of dibutyl glucarate and glucarolactones, which reduced the selectivity to FDCA esters and increased decarboxylation. However, addition of a catalytic amount of sulfuric acid as the co-catalyst gave FDCA in up to $70 \%$ yield. To our knowledge, these are the highest reported

Table 2 Production of furancarboxylates from esterified glucaric acid with solid acid catalysts

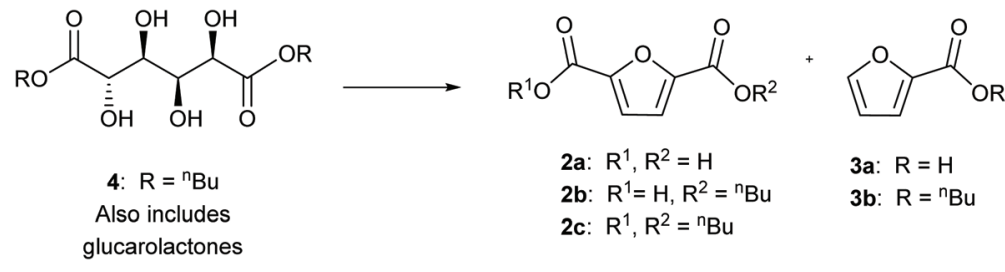

\begin{tabular}{|c|c|c|c|c|c|c|c|c|c|c|}
\hline \multirow[b]{2}{*}{ Entry } & \multirow[b]{2}{*}{ Catalyst } & \multirow[b]{2}{*}{ Cat. amount (wt\%) } & \multirow[b]{2}{*}{ Conv. (mol\%) } & \multicolumn{7}{|c|}{ Selectivity (mol\%) } \\
\hline & & & & $2 a$ & $2 \mathbf{b}$ & $2 c$ & $3 a$ & $3 \mathbf{b}$ & 2 & 3 \\
\hline 1 & PSAESS & 50 & 100 & 1 & 12 & 35 & 3 & 15 & 48 & 18 \\
\hline 2 & Si-Tosic acid & 50 & 100 & 0 & 14 & 38 & 0 & 8 & 52 & 8 \\
\hline 3 & Si-Tosic acid & 5 & 91 & 0 & 0 & 27 & 0 & 37 & 27 & 37 \\
\hline $4^{a}$ & Si-Tosic acid & 5 & 100 & 0 & 14 & 50 & 0 & 11 & 64 & 11 \\
\hline $5^{a}$ & Si-Tosic acid & 10 & 100 & 0 & 12 & 59 & 0 & 11 & 71 & 11 \\
\hline $6^{b}$ & - & & 100 & 0 & 9 & 41 & 0 & 10 & 50 & 10 \\
\hline
\end{tabular}

Reaction conditions: $7.4 \mathrm{mmol}$ mixture 4 (calculated based on average $M_{\mathrm{w}}$, see the ESI $\dagger$ ), $10 \mathrm{ml} n$-butanol, $220{ }^{\circ} \mathrm{C}, 4 \mathrm{~h}^{a}{ }^{a} 2.0 \mathrm{mmol} \mathrm{H}_{2} \mathrm{SO}_{4}$ added. ${ }^{b} 2.0 \mathrm{mmol} \mathrm{H}_{2} \mathrm{SO}_{4}$ added, $24 \mathrm{wt} \%$ insoluble char produced. 
yields of FDCA starting from aldaric acids. Finally, we also showed that esterification and aromatisation can be combined in a one-pot, two-step reaction.

\section{Experimental}

\section{Materials}

Galactaric acid (97\% purity), Nafion NR50 ( $\geq 90 \%$ assay, beads) and phenyl sulfonic acid ethyl sulfide silica (PSAESS, 95\% assay, $\geq 45 \mu \mathrm{m}$ particle size, $0.6-0.9 \mathrm{mmol} \mathrm{g}^{-1}$ loading) were obtained from Sigma Aldrich. Glucaric acid potassium salt ( $\geq 98 \%$ purity) was obtained from Santa Cruz. Silicotungstic acid (83.4\% $\mathrm{WO}_{3}$ assay) was obtained from Alfa Aesar. Si-Tosic acid $\left(0.62 \mathrm{meq} \mathrm{g}^{-1}, 40-63 \mu \mathrm{m}\right.$ particle size) and Si-propylsulfonic acid $\left(0.88 \mathrm{meq}^{-1}, 40-63 \mu \mathrm{m}\right.$ particle size) were obtained from SiliCycle.

\section{General method for the synthesis of aldaric acid esters}

Esterification of galactaric acid was carried out using Si-tosic acid and esterification of glucaric acid was performed using sulfuric acid. In a typical procedure, aldaric acid and $n$-butanol were placed in a three-neck flask and stirred with a magnetic stirrer. To this was added the acid catalyst, and the reaction mixture was heated to reflux for $24 \mathrm{~h}$. Once complete, the reaction mixture was hot-filtered $\left(80^{\circ} \mathrm{C}\right)$ over a porosity 3 sinter. Evaporation of the solvent $\left(45^{\circ} \mathrm{C}\right.$, less than 20 mbar) afforded the esterified aldaric acid. See the ESI $\dagger$ for detailed procedures and analyses.

\section{General method for producing furancarboxylates}

In a typical procedure, the weighed solvent, substrate and solid catalyst were added in a Hastelloy C-276 pressure reactor (75 ml) equipped with a magnetic stirring bar. The reactor was sealed and flushed with nitrogen before pressurising to approximately 5 bar with nitrogen. The reactor was then heated to the required reaction temperature (measured internally) for the indicated time. Magnetic stirring was used for mixing at $300 \mathrm{rpm}$. The reaction mixture was cooled to room temperature and filtered. Solvents were evaporated from the liquid phase (fraction 1) using a rotary evaporator and the residue was weighed. The solids from the first filtration were washed with $20 \mathrm{ml}$ of hot $n$-butanol. The solution from the second filtration (fraction 2) was evaporated using a rotary evaporator and then dried in a vacuum oven and weighed. Both isolated product fractions were analysed quantitatively with GC-FID using a Shimadzu GC-1020 Plus Gas Chromatograph equipped with a ZB-5HT Inferno column. GC-MS was used for product identification. Further purification of the products for NMR identification was carried out using Kugelrohr distillation. ${ }^{51}$

\section{Conflicts of interest}

The authors have no conflicts of interest to declare.

\section{Acknowledgements}

Funding from Business Finland is gratefully acknowledged.

\section{References}

1 J. J. Bozell and G. R. Petersen, Green Chem., 2010, 12, 539554.

2 B. M. Stadler, C. Wulf, T. Werner, S. Tin and J. G. de Vries, ACS Catal., 2019, 9, 8012-8067.

3 A. J. J. E. Eerhart, A. P. C. Faaij and M. K. Patel, Energy Environ. Sci., 2012, 5, 6407-6422.

4 Avantium YXY Technology, https:/www.avantium.com/ technologies/yxy/, (accessed June 2020).

5 J. K. Ogunjobi, T. J. Farmer, C. R. McElroy, S. W. Breeden, D. J. MacQuarrie, D. Thornthwaite and J. H. Clark, ACS Sustainable Chem. Eng., 2019, 7, 8183-8194.

6 L. Zhang, X. Luo, Y. Qin and Y. Li, RSC Adv., 2017, 7, 37-46.

7 J. Deng, X. Liu, C. Li, Y. Jiang and J. Zhu, RSC Adv., 2015, 5, 15930-15939.

8 A. Marotta, V. Ambrogi, P. Cerruti and A. Mija, RSC Adv., 2018, 8, 16330-16335.

9 M. Sajid, X. Zhao and D. Liu, Green Chem., 2018, 20, 54275453.

10 R. J. van Putten, J. C. van der Waal, E. de Jong, C. B. Rasrendra, H. J. Heeres and J. G. de Vries, Chem. Rev., 2013, 113, 1499-1597.

11 A. Mukherjee, M. J. Dumont and V. Raghavan, Biomass Bioenergy, 2015, 72, 143-183.

12 I. K. M. Yu and D. C. W. Tsang, Bioresour. Technol., 2017, 238, 716-732.

13 L. T. Mika, E. Cséfalvay and Á. Németh, Chem. Rev., 2018, 118, 505-613.

14 K. I. Galkin and V. P. Ananikov, ChemSusChem, 2019, 12, 2976-2982.

15 A. S. V. De Sousa Dias, G. J. M. Gruter and R. J. van Putten, US9090581B2, 2015.

16 C. Thoma, J. Konnerth, W. Sailer-Kronlachner, P. Solt, T. Rosenau and H. W. G. van Herwijnen, ChemSusChem, 2020, 13, 3544-3564.

17 H. Yuan, H. Liu, J. Du, K. Liu, T. Wang and L. Liu, Appl. Microbiol. Biotechnol., 2020, 104, 527-543.

18 Z. Zhang, J. Song and B. Han, Chem. Rev., 2017, 117, 68346880.

19 G. R. Dick, A. D. Frankhouser, A. Banerjee and M. W. Kanan, Green Chem., 2017, 19, 2966-2972.

20 F. van der Klis, J. van Haveren, D. S. van Es and J. H. Bitter, ChemSusChem, 2017, 10, 1460-1468.

21 R. Fittig, Chem. Ber., 1876, 9, 1189-1199.

22 R. Kuhn and K. Dury, Justus Liebigs Ann. Chem., 1951, 571, 44-68.

23 W. N. Haworth, W. G. M. Jones and L. F. Wiggins, J. Chem. Soc., 1945, 1, 1-4.

24 G. Brătulescu, Rev. Roum. Chim., 2000, 45, 883.

25 J. Lewkowski, Pol. J. Chem., 2001, 75, 1943. 
26 D. Zhao, F. Delbecq and C. Len, Molecules, 2019, 24, 8-10.

27 G. Bratulescu, J. Soc. Alger. Chim., 2000, 10, 135-137.

28 Y. Taguchi, A. Oishi and H. Iida, Chem. Lett., 2008, 37, 50-51.

29 T. Werpy and G. Petersen, Top Value Added Chemicals from Biomass: Volume I - Results of Screening for Potential Candidates from Sugars and Synthesis Gas, United States, 2004.

30 R. Archer, E. L. Dias, V. J. Murphy, T. R. Boussie, Z. M. Fresco, J. Shoemaker and H. Jiang, WO2010144862A2, 2010.

31 T. N. Smith, K. Hash, C.-L. Davey, H. Mills, H. Williams and D. E. Kiely, Carbohydr. Res., 2012, 350, 6-13.

32 V. B. Thaore, R. D. Armstrong, G. J. Hutchings, D. W. Knight, D. Chadwick and N. Shah, Chem. Eng. Res. Des., 2020, 153, 337-349.

33 S. Rautiainen, P. Lehtinen, J. Chen, M. Vehkamäki, K. Niemelä, M. Leskelä and T. Repo, RSC Adv., 2015, 5, 19502-19507.

34 F. van der Klis, A. E. Frissen, J. van Haveren and D. S. van Es, ChemSusChem, 2013, 6, 1640-1645.

35 D. S. J. van Esvan Haveren, H. W. C. Raaijmakers, F. van der Klis, G. P. F. M. van Engelen and A. E. Frissen, US9079844B2, 2015.

36 F. van der Klis, L. Gootjes, J. van Haveren, D. S. van Es and J. H. Bitter, React. Chem. Eng., 2018, 3, 540-549.

37 D. Mojzita, M. Wiebe, S. Hilditch, H. Boer, M. Penttilä and P. Richard, Appl. Environ. Microbiol., 2010, 76, 169-175.
38 H. Boer, S. Hildich, M. Penttilä and P. Richard, US8895273B2, 2015.

39 S. Kambourakis, B. M. Griffin and K. V. Martin, US9528133B2, 2017.

40 T. Paasikallio, A. Huuskonen and M. G. Wiebe, Microb. Cell Fact., 2017, 16, 119.

41 I. Khalil, G. Quintens, T. Junkers and M. Dusselier, Green Chem., 2020, 22, 1517-1541.

42 M. Shiramizu and F. D. Toste, Angew. Chem., Int. Ed., 2013, 52, 12905-12909.

43 X. Li, D. Wu, T. Lu, G. Yi, H. Su and Y. Zhang, Angew. Chem., Int. Ed., 2014, 53, 4200-4204.

44 B. Hočevar, M. Grilc and B. Likozar, Catalysts, 2019, 9, 286.

45 N. Shin, S. Kwon, S. Moon, C. H. Hong and Y. G. Kim, Tetraherdon, 2017, 73, 4758-4765.

46 D. Thomas, A. Harlin and M. Asikainen, US10301276B2, 2019.

47 D. Thomas, A. Harlin and M. Asikainen, US9969669B2, 2018.

48 Shagufta, I. Ahmad and R. Dhar, Catal. Surv. Asia, 2017, 21, 53-69.

49 A. J. Crisci, M. H. Tucker, M. Lee, S. G. Jang, J. A. Dumesic and S. L. Scott, ACS Catal., 2011, 1, 719-728.

50 J. M. Brown, M. Manley-Harris, R. J. Field and D. E. Kiely, J. Carbohydr. Chem., 2007, 26, 455-467.

51 D. Thomas and J. Linnekoski, WO2019155127A1, 2019. 